\title{
PEMERINGKATAN PENILAIAN KINERJA KARYAWAN MELALUI METODE AHP DAN VIKOR
}

\author{
Wina Yusnaeni' ${ }^{1}$ Marlina² \\ Program Studi Sistem Informasi ${ }^{1}$ \\ Universitas Bina Sarana Informatika \\ www.bsi.ac.id \\ wina.wyi@bsi.ac.id ${ }^{1}$ \\ Program Studi Sistem Informasi Akuntansi² \\ Universitas Bina Sarana Informatika \\ www.bsi.ac.id \\ $\underline{\text { marlina.mln@bsi.ac.id }}{ }^{2}$
}

\begin{abstract}
In the company can not be separated from human resources, which is an important part of the company. The success of a company depends on the resources that are in it. Therefore, human resources have a very vital role. One of the most important factors in a company, human resources must be considered for their welfare and appreciation. For example, giving appreciation for employee performance. From evaluating employee performance, exact calculations are required, one of which uses AHP and Vikor methods. The result of this research showed usage method of vikor who assists in assessment has raised the of employee performance based on the criteria of which there are, Where criteria have been in appointed by the company and provision of weight of criteria with the methods ahp. From the results of the count it over with ahp drugs got when the the value of weighted criteria in accordance with the provisions fees for civil servant employees ahp with a value of The $C R \leq$ 0.1. This is done to explain the consistency of the weight of the criteria which had been assessed by the judges. Next, with Vikor method, obtained with the smallest value in the calculation of $V=0.5$. from the results of the performed calculations to see stability calculation results with alternative methods of vikor 1 way obtained Value $Q$ (2) $Q$ (1) $\geq D Q$, and obtained also for method 2 using the value $V=0.4$ and value $V=0.6$ and gained equality results ranked one and two. The result of the method of vikor expected can help decision-makers in determining the ranking of employees based on the best performance of employees.
\end{abstract}

Key : performance assessment, AHP, Vikor

Intisari- Di perusahaan tidak lepas dari sumber daya manusia, dimana merupakan bagian penting dalam perusahaan. Keberhasilan suatu perushaan bergantung pada sumber daya yang ada didalamnya. Oleh karena itu, sumber daya manusia memiliki peranan sangat vital. Sebagai salah satu faktor yang sangat penting dalam perusahaan maka sumber daya manusia harus diperhatikan kesejahteraannya dan apresiasi yang diberikan. Sebagai contoh memberikan apresiasi untuk kinerja karyawan. Namun dalam penilaian kinerja karyawan tentunya diperlukan perhitungan yan tepat salah satunya menggunakan metode AHP dan Vikor. Dari hasil penelitian memperlihatkan penggunaan metode Vikor yang membantu dalam pemeringkatan kinerja karyawan berdasarkan kriteria yang ada, dimana kriteria telah di tetapkan oleh perusahaan serta pemberian bobot dari kriteria dengan metode AHP. Dari hasil perhitungan dengan AHP didapat nilai bobot kriteria sesuai dengan ketentuan perhitungan AHP dengan nilai $\mathrm{CR} \leq 0.1$, hal ini dilakukan untuk menjelaskan konsistensi bobot kriteria yang telah dinilai oleh tim penilai. Selanjutnya, di olah dengan dengan metode Vikor, didapat dengan nilai terkecil dari perhitungan $\mathrm{V}=0.5$. dari hasil tersebut maka dilakukan perhitungan untuk melihat stabilitas alternative hasil perhitungan dengan metode vikor dengan cara 1 didapat Nilai Q(2)$\mathrm{Q}(1) \geq \mathrm{DQ}$. dan didapat juga untuk cara 2 dengan menggunakan Nilai $\mathrm{V}=0.4$ dan nilai $\mathrm{V}=0.6$ dan didapat adanya persamaan hasil peringkat satu dan dua. Dari hasil tersebut Metode vikor diharapkan bisa membantu para pengambil keputusan dalam menentukan pemeringkatan karyawan berdasarkan kinerja terbaik karyawan.

Kata Kunci: Penilaian Kinerja, AHP, Vikor.

\section{PENDAHULUAN}

Suatu perusahaan tidak lepas dari sumber daya manusia (SDM), sumber daya manusia merupakan bagian terpenting dalam suatu perusahaan dalam hal ini adalah karyawan yang bekerja di dalamnya, dimana berhasil tidaknya suatu perusahaan 
berjalan dengan baik tidak lepas dari peran karyawan. Seperti yang telah kita ketahui bersama, bahwa sumber daya manusia memiliki peranan yang sangat vital (Ayunungsih, Prihambodo, Susilowati, \& SK, 2011) bagi sebuah perusahaan. Salah satu kegiatan penting dari manajemen sumber daya manusia adalah penilaian kinerja karyawan. Tentu saja setiap perusahaan menginginkan karyawan yang memiliki kinerja sesuai dengan standar yang telah ditetapkan perusahaan sebelumnya atau bahkan melebihinya (Santoso, Fathoni, \& Hasiholan, 2018). Dengan dilakukannya penilaian kinerja terhadap karyawan, maka akan memberikan gambaran pada perusahaan seperti apa perilaku karyawan berkaitan dengan pekerjaannya serta informasi perihal penetapan kompensasi, pelatihan dan pengembangan, promosi karyawan, dan lainlain (Siti Noni Evita,Wa Ode Zusnita Muizu, 2017).

PT. Wisdom Indonesia Sejahtera merupakan suatu perusahaan yang bergerak di bidang distributor sound audio dalam upaya peningkatan prestasi dan kinerja karyawan maka perlunya motivasi terhadap karyawan bisa berupa reward, kenaikan pangkat atau lain-lainnya.

Kinerja karyawan adalah tingkat hasil kerja karyawan dalam mencapai persyaratanpersyaratan yang diberikan. Kinerja karyawan juga dapat diartikan hasil kerja secara kuantitas yang dicapai seorang karyawan dalam melaksanakan tugas sesuai dengan tanggung jawab yang diberikan (Ulfa, Maria, Ridwan, 2015). Seperti yang dikemukakan oleh Mathis dan Jackson bahwa Penilaian kinerja karyawan adalah proses mengevaluasi seberapa baik karyawan melakukan pekerjaan mereka jika dibandingkan dengan seperangkat standar dan kemudian mengkomunikasikan informasi tersebut pada karyawan (Hidayat, 2015). maka penilaian kinerja dapat dikatakan efektif apabila meliputi dua hal, yaitu (1) adanya seperangkat standar dan (2) komunikasi informasi (umpan balik) (Hidayat, 2015). Selain itu, penilaian yang masih bersifat subyektif dan belum relevan dengan keadaan sebenarnya sehingga tidak dapat digunakan sebagai dasar pengambilan keputusan yang bersifat objektif dan pihak rumah sakit kesulitan dalam menentukan prestasi kinerja (Saefudin \& Wahyuningsih, 2014).

Berdasarkan penjabaran permasalahan diatas maka diperlukan sistem pendukung keputusan yang dapat menyeleksi dari kriteria masing-masing dari yang telah ditentukan. Disini penulis mencoba untuk menggunakan metode AHP dan vikor dalam penyelesaiannya. Dimana penggunaan analisis AHP dalam pembobotan kriteria yang yang digunakan dalam metode Vikor (Wijaya \& Mesran, 2019). Dimana AHP memiliki kelebihan dalam konsistensi dan penentuan bobot kriteria. Selain itu, dalam penelitian (Opricovic, 2004) dalam (Lengkong, Permanasari, \& Fauziati, 2015) menjelaskan tentang perbandingan metode Topsis dan Vikor yang menjelaskan bahwa metode Vikor lebih mendekati solusi ideal.

\section{BAHAN DAN METODE}

\section{A. Rancangan Penelitian}

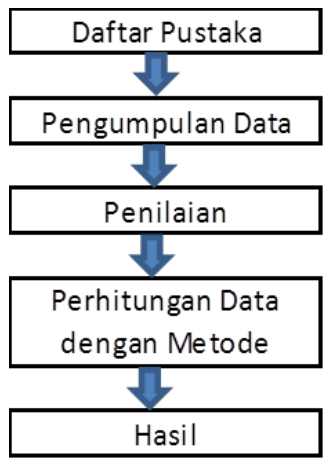

Sumber : (Wina Yusnaeni, 2019)

Gambar 1. Rancangan Penelitian

Rancangan Penelitian berdasarkan Tahapan diatas sebagai berikut:

1. Daftar Pustaka

Melakukan pencarian referensi tentang metode AHP dan Vikor.

\section{Pengumpulan data}

Menngumpulkan data penilaian dan bobot dari penilai. Selanjutnya akan di lakukan penentuan variabel dari kritera dan alternative.

\section{Penilaian}

Dilakukan Penilaian dengan menggunakan form kuisioner untuk menilai bobot kriteria dengan kuisioner AHP serta penilaian kriteria terhadap alternative dengan ketentuan penilaian bobot yang telah ditentukan.

4. Perhtungan data dengan metode

Data yang didapat akan di rekap dan diolah dengan metode AHP dan Vikor.

\section{Hasil}

Hasil dari pengolahan data berupa pemeringkatan hasil pengolahan bobot kriteria dan alternatif.

\section{B. Sumber Data}

Sumber data didapat dari PT. Wisom Indonesia Sejahtera dengan hasil perbandingan kriteria dan nilai bobot. Dimana ketentuan nilai bobot sesuai dengan yang telah ada di perusahaan. Dimana penilaian dilakukan terhadapa 11 karyawan yang 
terpilih dan layak menurut pimpinan. Penilaian dilakukan oleh tiga orang penilai yang dianggap layak sebagai pengambil keputusan.

\section{Teknik Analisis Data}

Tahapan analisis data metode Ahp dan Vikor (Gede Suwardika, 2018):

1. Tahapan menentukan bobot kriteria dengan AHP:

a. Membuat perbandingan berpasangan dari setiap kriteria

b. Normalisasi Matrik berpasangan

c. Mengolah prioritas relatif dari setiap kriteria

d. Mengukur konsistensi setiap kriteria

e. Menghitung nilai consisteny index (CI)

f. Menghitung cinsistency ratio (CR)

g. Memeriksa konsistensi penentuan bobot, bila CR kurang dari atau sama dengan 0,1 maka penentuan bobot konsisten, tetapi bila CR lebih besar dari 0,1 maka penentuan bobot kriteria harus diulang kembali.

2. Tahapan Vikor

a) Membuat matriks keputusan dari alternatif dengan ukuran $F_{n x c}$, dengan rumus sebagai berikut:

b)

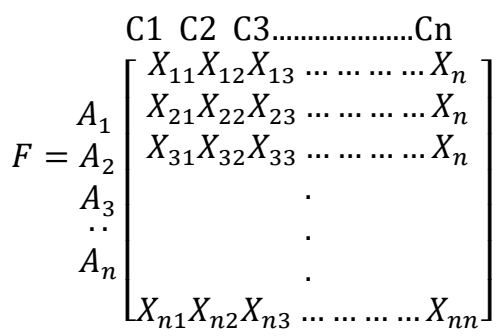

Dimana $A_{i}$ alternatif $k e-i=1,2 \ldots . . . n, \quad C$ merupakan kriteria ke-j dan $\mathrm{X}_{\mathrm{ij}}$ adalah elemen dari matriks yang menunjukan tingkatan kinerja dari alternatif ke-i.

c) Menghitng nilai positif dan negatif sebagai solusi ideal, dimana nilai positif merupakan nilai tertinggi dan negatif merupakan nilai terkecil.

$$
\begin{aligned}
f_{j}^{*} & =\left\{\min f_{i j} \mid j=1,2, \ldots \ldots, c\right\} \ldots \ldots \\
& =f_{1}^{*}, f_{2}^{*}, \ldots \ldots, f_{j}^{*}, \ldots \ldots, f_{c}^{*} \\
f_{j}^{-} & =\left\{\max f_{i j} \mid j=1,2, \ldots . ., c\right\} \ldots \\
& =f_{1}^{-}, f_{2}^{-}, \ldots \ldots, f_{j}^{-}, \ldots \ldots, f_{c}^{-}
\end{aligned}
$$

d) Melakukan normalisasi untuk menghasilkan matriks decision yang baru dari data dengan ukuran $\mathrm{N}_{\mathrm{nxc}}$, dengan rumus:

$$
N_{i j}=\frac{f_{i j}^{*}-X_{i j}}{f_{i j}^{*}-f_{i j}^{-}}
$$

e) Menghitung matriks normalisasi dengan bobot, dengan rumus: $F_{i j}=N_{i j} x W_{i}$
$W_{i}$ merupakan bobot yang dihitung dengan menggunakan AHP dengan banyaknya perhitungan $F_{n x c}$.

f) Menghitung utility measure, dengan rumus:

$S_{i}=\sum_{j=1}^{6} F_{i j}$

$\mathrm{R}_{\mathrm{i}}=\operatorname{Max}\left(\mathrm{F}_{\mathrm{i} 1}, \mathrm{~F}_{\mathrm{i}}\right.$

$\mathrm{S}^{+}=\operatorname{Max}\left(\mathrm{S}_{1}, \mathrm{~S}_{2}, \mathrm{~S}_{3}, \ldots \ldots \ldots \ldots . . . \mathrm{S}_{\mathrm{ij}}\right)$

$\mathrm{S}=\operatorname{Min}\left(\mathrm{S}_{1}, \mathrm{~S}_{2}, \mathrm{~S}_{3}, \ldots \ldots \ldots \ldots . . . \mathrm{Sij}\right)$

$\mathrm{R}^{+}=\operatorname{Max}(\mathrm{R} 1, \mathrm{R} 2, \mathrm{R} 3, \ldots \ldots \ldots . . . \mathrm{Rij})$

$\mathrm{R}^{-}=\mathrm{Min}(\mathrm{R} 1, \mathrm{R} 2, \mathrm{R} 3, \ldots \ldots \ldots . . . \mathrm{Rij})$

g) Menghitung indeks VIKOR (Q), dengan rumus sebagai berikut:

$Q_{j}=\left[v \frac{S_{j}-S^{-}}{S^{+}-S^{-}}\right]+\left[(1-v) \frac{R_{j}-R^{-}}{R^{+}-R^{-}}\right]$

h) Pemeringkatan alternatif dari Nilai VIKOR

Setelah didapat nilai $\mathrm{Q}, \mathrm{R}$, dan $\mathrm{S}$ perangkingan bisa diperiksa dengan kondisi:

1. Diterima apabila : $\mathrm{Q}(2)-\mathrm{Q}(1)>=\mathrm{DQ}$, dengan $\mathrm{DQ}=\frac{1}{(n-1)} \mathrm{xA} 1$

2. Kondisi 2: Diterima jika melihat dari stabilitas perangkingan alternative. Stabilitas Alternative dinilai ketika nilai $\mathrm{V}=0.5$ Atau $\mathrm{V}<=0,5$ Atau $\mathrm{V}>=0,5$

Jika salah satu kondisi tidak memuaskan, selanjutnya solusi kompromi dapat dilihat sebagai berikut :

Memilih Alternative A1 dan A2 jika hanya kondisi 2 tidak memuaskan atau; Memilih alternatif $A 1, A 2, \ldots$ , An jika kondisi 1 tidak memuaskan. An merupakan alternatif yang ditentukan dengan menggunakan persamaan:

$\mathrm{Q}(\mathrm{n})-\mathrm{Q}(1)<\mathrm{DQ}$, dengan $\mathrm{DQ}=\frac{1}{(n-1)} \mathrm{XA} 1$

\section{Data Kriteria, Alternative}

Data kriteria tingkat bobot penilaian, data alternative serta penilaian dilakukan melalui wawancara dan pemberian kuisioner penilaian kriteria dan alternative dengan bobot yang telah ditentukan. Penilaian dilakukan oleh tiga orang yang dianggap mampu dalam pengambilan keputusan dalam suatu perusahaan.

Untuk bobot penilaian alternative terhadap kriteria, yaitu:

Tabel 1. Bobot Penilaian

\begin{tabular}{cl}
\hline Bobot & Keterangan \\
\hline $\mathbf{1}$ & Sangat Rendah \\
$\mathbf{2}$ & Rendah \\
$\mathbf{3}$ & Cukup \\
$\mathbf{4}$ & Tinggi \\
$\mathbf{5}$ & Sangat Tinggi \\
\hline
\end{tabular}

Sumber : (Sejahtera, 2019)

Untuk kriteria yang digunakan : 
Tabel 2. Kriteria penilaian

\begin{tabular}{cl}
\hline Kode Kriteria & \multicolumn{1}{c}{ Nama Kriteria } \\
\hline KR1 & Kehadiran \\
KR2 & Hasil Penjualan \\
KR3 & Atitude \\
KR4 & Lama Bekerja \\
KR5 & Latar Belakang Pendidikan \\
\hline Sut
\end{tabular}

Sumber : (Sejahtera, 2019)

Alternative yang dinilai terdiri dari 11 karyawan:

Tabel 3. Data Alternative

\begin{tabular}{ll}
\hline Kode & \multicolumn{1}{c}{ Nama Karyawan } \\
\hline KRY1 & Rosita \\
KRY2 & Riani \\
KRY3 & Latifah \\
KRY4 & Wulandari \\
KRY5 & Ani \\
KRY6 & Yuli \\
KRY7 & Ambaryana \\
KRY8 & Ali \\
KRY9 & Rohman \\
KRY10 & Sodik \\
KRY11 & Riswan \\
\hline
\end{tabular}

Sumber : (Sejahtera, 2019)

\section{E. Relevansi penelitian}

Berikut beberapa relevansi penelitian:

Tabel 4. Relevansi penelitian

\begin{tabular}{lll}
\hline No & Penulis & Judul Penelitian \\
\hline $\mathbf{1}$ & (Rahadjeng \& & Penerapan Data Mining \\
& Sumarno, 2019) & Dalam Penilaian Kinerja Guru \\
& & Tetap SD Negeri Kebalen 07 \\
& & Dengan Metode TOPSIS \\
$\mathbf{2}$ & (Saefudin \& & Sistem Pendukung \\
& Wahyuningsih, & Keputusan Untuk Penilaian \\
& 2014) & Kinerja Pegawai \\
& & Menggunakan Metode \\
& & Analytical Hierarchy Process \\
& & (Ahp) Pada RSUD Serang \\
& (Gede Suwardika, & Penerapan Metode VIKOR \\
& 2018) & pada Pengambilan \\
& & Keputusan Seleksi Calon \\
& & Penerima Beasiswa Bidikmisi \\
$\mathbf{4}$ & (Sutrikanti, & Universitas Terbuka \\
& Situmorang, \& & Implementasi Pendukung \\
& Nurdiyanto, 2018) & Keputusan Dalam Pemilihan \\
& & Calon Peserta Cerdas Cermat \\
& & Tingkat SMA Menerapkan \\
& & Metode VIKOR \\
& & Nidia \\
& (Siti Noni Evita,Wa & Penilaian Kinerja Karyawan \\
& Ode Zusnita Muizu, & Dengan Menggunakan \\
& 2017) & Metode Behaviorally Anchor \\
& & Rating Scale Dan \\
& & Management By Objectives \\
& & (Studi Kasus Pada Pt Qwords \\
& & Company International) \\
\hline & &
\end{tabular}

Sumber:(Wina Yusnaeni, 2019)

\section{HASIL DAN PEMBAHASAN}

Dalam langkah pengolahan data dengan metode dilakukan perekapan data bobot kriteria dengan metode AHP. Dari kuisioner bobot kriteria di dapat data sebagai berikut:

Tabel 5. Tabel bobot dengan menggunakan ahp

\begin{tabular}{lccccc}
\hline \multicolumn{1}{c}{ Kriteria } & $\begin{array}{l}\text { Keha } \\
\text { diran }\end{array}$ & $\begin{array}{l}\text { Hasil } \\
\text { Penjuala } \\
\mathbf{n}\end{array}$ & $\begin{array}{l}\text { Atit } \\
\text { ude }\end{array}$ & $\begin{array}{l}\text { Lama } \\
\text { Bekerja }\end{array}$ & $\begin{array}{l}\text { Latar } \\
\text { Belaka } \\
\text { ng }\end{array}$ \\
\hline Kehadiran & 1 & 3 & 0.33 & 0.25 & $\begin{array}{l}\text { Pendi } \\
\text { dikan }\end{array}$ \\
Hasil Penjualan & 0.333 & 1 & 0.50 & 0.25 & 0.333 \\
Atitude & 3 & 2 & 1 & 0.500 & 0.333 \\
Lama Bekerja & 4 & 4 & 2 & 1 & 0.50 \\
$\begin{array}{l}\text { Latar Belakang } \\
\text { Pendidikan }\end{array}$ & 2 & 3 & 3 & 2 & 1 \\
\hline
\end{tabular}

Sumber: (Wina Yusnaeni, 2019)

Selanjut untuk menentukan bobot dari kriteria dilakukan tahapan :

1. Normalisasi Matrik berpasangan

Tabel 6. Normalisasi Matrik Berpasangan

\begin{tabular}{|c|c|c|c|c|c|}
\hline & KR1 & KR2 & KR3 & KR4 & KR5 \\
\hline & 0.096774194 & 0.230769231 & 0.0487805 & 0.0625 & 0.1875 \\
\hline & 0.032258065 & 0.076923077 & 0.0731707 & 0.0625 & 0.125 \\
\hline \multirow{3}{*}{$N=$} & 0.290322581 & 0.153846154 & 0.1463415 & 0.125 & 0.125 \\
\hline & 0.387096774 & 0.307692308 & 0.2926829 & 0.25 & 0.1875 \\
\hline & 0.193548387 & 0.230769231 & 0.4390244 & 0.5 & 0.375 \\
\hline
\end{tabular}

Sumber : (Wina Yusnaeni, 2019)

2. Mengolah prioritas relatif dari setiap kriteria

Tabel 7. Bobot Prioritas Setiap Kriteria

\begin{tabular}{lr}
\hline & prioritas relatif (PR) setiap kriteria \\
\hline JBN1 & 0.125264782 \\
\hline JBN2 & 0.073970375 \\
\hline JBN3 & 0.16810204 \\
\hline JBN4 & 0.284994402 \\
\hline JBN5 & 0.347668402 \\
\hline
\end{tabular}

Menentukan Consisteny index (CI) 
Tabel 8. Jumlah matrik perbaris

\begin{tabular}{lrrrrr} 
& 0.125264782 & 0.221911124 & 0.056034 & 0.0712486 & 0.173834201 \\
& 0.041754927 & 0.073970375 & 0.084051 & 0.0712486 & 0.115889467 \\
& 0.375794347 & 0.147940749 & 0.168102 & 0.142497201 & 0.115889467 \\
& 0.50105913 & 0.295881499 & 0.3362041 & 0.284994402 & 0.173834201 \\
& 0.250529565 & 0.221911124 & 0.5043061 & 0.569988803 & 0.347668402 \\
\hline $\mathbf{K}=\mathbf{C I}=$ & 5.418713876 & & & \\
\hline
\end{tabular}

3. Menentukan nilai CR

$\frac{\mathrm{CR}=0.093462919}{\text { Dari hasil CR diatas Nilai CR } \leq 0.1}$

\section{Metode Vikor}

Rekap Penilaian Alternative terhadap Kriteria dari tiga penilai :

Nilai Prioritas Bobot W:

\begin{tabular}{lr} 
Tabel 9. Nilai Bobot Kriteria \\
\hline & $\begin{array}{c}\text { prioritas relatif } \\
\text { (PR) setiap kriteria }\end{array}$ \\
\hline JBN1 & 0.125264782 \\
JBN2 & 0.073970375 \\
JBN3 & 0.16810204 \\
JBN4 & 0.284994402 \\
JBN5 & 0.347668402 \\
\hline
\end{tabular}

1) Langkah 1 dan 2 Membuat matriks keputusan dari alternatif dan Menghitng nilai positif dan negatif sebagai solusi ideal:

Tabel 10. Rata-rata bobot Alternative terhadap

\begin{tabular}{cccccc}
\multicolumn{6}{c}{ kriteria } \\
\hline & K1 & K2 & K3 & K4 & K5 \\
\hline KRY1 & 4.33 & 4.67 & 4.33 & 5.00 & 4.33 \\
KRY2 & 4.00 & 4.33 & 4.67 & 3.67 & 3.67 \\
KRY3 & 4.67 & 4.00 & 3.67 & 4.33 & 4.00 \\
KRY4 & 3.67 & 3.67 & 4.33 & 4.67 & 4.00 \\
KRY5 & 4.00 & 3.33 & 4.33 & 3.67 & 3.67 \\
KRY6 & 4.67 & 4.67 & 5.00 & 5.00 & 4.00 \\
KRY7 & 4.33 & 4.00 & 4.33 & 4.00 & 3.33 \\
KRY8 & 4.33 & 4.33 & 4.33 & 4.33 & 5.00 \\
KRY9 & 5.00 & 4.33 & 4.33 & 4.33 & 4.33 \\
KRY10 & 4.00 & 4.00 & 4.33 & 4.33 & 4.33 \\
KRY11 & 4.67 & 4.33 & 4.33 & 4.67 & 4.00 \\
\hline Max & 5 & 5 & 5 & 5 & 5 \\
Min & 4 & 3 & 4 & 4 & 3 \\
\hline Sumber: & & &
\end{tabular}

Sumber: (Wina Yusnaeni, 2019)
2) Langkah 3 Melakukan normalisasi untuk menghasilkan matriks decision

Tabel 11. Nilai Solusi Ideal

\begin{tabular}{rcrrrr}
\hline K1 & K2 & K3 & K4 & K5 \\
\hline $\mathbf{0 . 5}$ & 0.00 & 0.5 & 0 & 0.4 \\
$\mathbf{0 . 7 5}$ & 0.25 & 0.25 & 1 & 0.8 \\
$\mathbf{0 . 2 5}$ & 0.50 & 1 & 0.5 & 0.6 \\
$\mathbf{1}$ & 0.75 & 0.5 & 0.25 & 0.6 \\
$\mathbf{0 . 7 5}$ & 1.00 & 0.5 & 1 & 0.8 \\
$\mathbf{0 . 2 5}$ & 0.00 & 0 & 0 & 0.6 \\
$\mathbf{0 . 5}$ & 0.50 & 0.5 & 0.75 & 1 \\
$\mathbf{0 . 5}$ & 0.25 & 0.5 & 0.5 & 0 \\
$\mathbf{0}$ & 0.25 & 0.5 & 0.5 & 0.4 \\
$\mathbf{0 . 7 5}$ & 0.50 & 0.5 & 0.5 & 0.4 \\
$\mathbf{0 . 2 5}$ & 0.25 & 0.5 & 0.25 & 0.6 \\
\hline
\end{tabular}

Sumber: (Wina Yusnaeni, 2019)

\section{3) Langkah 4 Menghitung matriks normalisasi dengan bobot}

Tabel 12. Matrik Normalisasi dengan Bobot

\begin{tabular}{lllll}
\hline K1 & K2 & K3 & K4 & K5 \\
\hline $\mathbf{0 . 0 6 3}$ & 0.000 & 0.084 & 0.000 & 0.139 \\
$\mathbf{0 . 0 9 4}$ & 0.018 & 0.042 & 0.285 & 0.278 \\
$\mathbf{0 . 0 3 1}$ & 0.037 & 0.168 & 0.142 & 0.209 \\
$\mathbf{0 . 1 2 5}$ & 0.055 & 0.084 & 0.071 & 0.209 \\
$\mathbf{0 . 0 9 4}$ & 0.074 & 0.084 & 0.285 & 0.278 \\
$\mathbf{0 . 0 3 1}$ & 0.000 & 0.000 & 0.000 & 0.209 \\
$\mathbf{0 . 0 6 3}$ & 0.037 & 0.084 & 0.214 & 0.348 \\
$\mathbf{0 . 0 6 3}$ & 0.018 & 0.084 & 0.142 & 0.000 \\
$\mathbf{0 . 0 0 0}$ & 0.018 & 0.084 & 0.142 & 0.139 \\
$\mathbf{0 . 0 9 4}$ & 0.037 & 0.084 & 0.142 & 0.139 \\
$\mathbf{0 . 0 3 1}$ & 0.018 & 0.084 & 0.071 & 0.209 \\
\hline
\end{tabular}

Sumber : (Wina Yusnaeni, 2019)

4) Langkah 5 dan 6 Menghitung utility measure dan $f$ Menghitung indeks VIKOR (Q).

Menghitung perangkingan Qi merupakan perangkingan kompromi dengan menghitung indeks VIKOR. 
Tabel 13. Nilai R, S, dan Q

\begin{tabular}{lll}
\hline $\mathbf{R}$ & $\mathbf{S}$ & $\mathbf{Q}$ \\
\hline $\mathbf{0 . 1 3 9 0 6 7}$ & 0.285751 & 0.039843 \\
$\mathbf{0 . 2 8 4 9 9 4}$ & 0.717596 & 0.765017 \\
$\mathbf{0 . 2 0 8 6 0 1}$ & 0.587502 & 0.468818 \\
$\mathbf{0 . 2 0 8 6 0 1}$ & 0.544643 & 0.431562 \\
$\mathbf{0 . 2 8 4 9 9 4}$ & 0.815099 & 0.849775 \\
$\mathbf{0 . 2 0 8 6 0 1}$ & 0.239917 & 0.166667 \\
$\mathbf{0 . 3 4 7 6 6 8}$ & 0.745083 & 0.939136 \\
$\mathbf{0 . 1 4 2 4 9 7}$ & 0.307673 & 0.067121 \\
$\mathbf{0 . 1 4 2 4 9 7}$ & 0.384108 & 0.133565 \\
$\mathbf{0 . 1 4 2 4 9 7}$ & 0.496549 & 0.231309 \\
$\mathbf{0 . 2 0 8 6 0 1}$ & 0.413709 & 0.317743 \\
\hline
\end{tabular}

Sumber : (Wina Yusnaeni, 2019)

Pemeriksaan perangkingan dengan menggunakan cara 1:

Nilai $D Q=0.003984265$, Nilai $Q(2)-Q(1) \geq D Q=$ 0.027278011 . berdasarkan diatas maka nilai $Q$ memenuhi dengan nilai $\geq \mathrm{DQ}$.

Cara 2:

Stabilitas Alternative dinilai ketika nilai $\mathrm{V}=0.5$ Atau $\mathrm{V}<=0,5(\mathrm{~V}=0.4)$ Atau $\mathrm{V}>=0,5(\mathrm{~V}=0.6)$

Hasilnya:

Tabel 14. Hasil perhitungan dengan $Q=0.5$ $\mathrm{Q}=0.4$ dan $\mathrm{Q}=0.6$

\begin{tabular}{lrr}
\hline $\begin{array}{l}\text { Q dengan } \\
\text { V=0.5 }\end{array}$ & \multicolumn{1}{c}{$\begin{array}{c}\text { Q dengan } \\
\mathbf{V}=\mathbf{0 . 4}\end{array}$} & \multicolumn{1}{c}{$\begin{array}{c}\text { dengan } \\
\mathbf{V}=\mathbf{0 . 6}\end{array}$} \\
\hline $\mathbf{0 . 0 3 9 8 4 3}$ & 0.031874 & 0.047811 \\
$\mathbf{0 . 7 6 5 0 1 7}$ & 0.751924 & 0.77811 \\
$\mathbf{0 . 4 6 8 8 1 8}$ & 0.441721 & 0.495915 \\
$\mathbf{0 . 4 3 1 5 6 2}$ & 0.411916 & 0.451208 \\
$\mathbf{0 . 8 4 9 7 7 5}$ & 0.819731 & 0.87982 \\
$\mathbf{0 . 1 6 6 6 6 7}$ & 0.2 & 0.133333 \\
$\mathbf{0 . 9 3 9 1 3 6}$ & 0.951308 & 0.926963 \\
$\mathbf{0 . 0 6 7 1 2 1}$ & 0.056985 & 0.077256 \\
$\mathbf{0 . 1 3 3 5 6 5}$ & 0.11014 & 0.156989 \\
$\mathbf{0 . 2 3 1 3 0 9}$ & 0.188336 & 0.274282 \\
$\mathbf{0 . 3 1 7 7 4 3}$ & 0.320861 & 0.314624 \\
\hline
\end{tabular}

Sumber : (Wina Yusnaeni, 2019)

Dilihat setelah pengolahan dengan nilai $\mathrm{v}=0.5$, $\mathrm{v}=0.4$ dan $\mathrm{v}=0.6$, perangkingan dengan urutan dan kedua tidak mengalamai perubahan meskipun data lain ada sedikit perubahan.

\section{KESIMPULAN}

Hasil Penelitian memperlihatkan bahwa :
1. Konsistensi bobot kriteria yang dihitung dengan metode Ahp dengan nilai $\mathrm{CR} \leq 0.1$.

2. Di dapat perangkingan dengan menggunakan metode vikor yaitu dengan nilai terkecil adalah 0.039843 .

3. Dilakukan solusi kompromi dengan dua solusi dan didapat hasil dengan solusi pertama $\mathrm{Q}(2)-\mathrm{Q}(1) \geq \mathrm{DQ}$, di dapat nilai $0.027278011 \geq$ 0.003984265 . sehingga solusi pertama diterima. Selanjutnya dengan solusi kompromi yang kedua dengan melakukan perhitungan perangkingan dengan nilai $Q<0,5$ yaitu diambil nilai $Q=0,4$ dan nilai $Q>0,5$ diambil nilai $Q=0,6$. Hasilnya berupa konsistensi perangkingan posisi 1 dan 2 . maka, solusi kompromi kedua diterima.

4. Hal ini membuktikan bahwa solusi dengan solusi kompromi 1 dan 2 terpenuhi dan dapat dijadikan sebagai solusi dalam pemeringkatan kinerja karyawan pada PT. Wisdom Indonesia Sejahtera.

Untuk penelitian Selanjutnya, adanya pengolahan data dengan data mining sehingga data lebih bervariasi. Selain itu bisa ditambahkan sistem informasi sehingga pengolahan dan perhitungan menjadi lebih mudah.

\section{REFERENSI}

Ayunungsih, D. M., Prihambodo, A., Susilowati, A. Y., \& SK, R. S. N. (2011). Pengelolaan Sumber Daya Manusia Dalam Bisnis Hotel Studi komparasi di Hotel Duta Garden, Hotel Wisanti, Hotel Musafira dan Hotel Perwita Sari Yogyakarta. Jurnal Manajemen, 1(1), 1425. https://doi.org/10.26460/jm.v1i1.130

Gede Suwardika, I. K. P. S. (2018). Penerapan Metode VIKOR pada Pengambilan Keputusan Seleksi Calon Penerima Beasiswa Bidikmisi Universitas Terbuka. INTENSIF, 2(1), 24-35.

Hidayat, R. (2015). Performance Appraisal sebagai Alat Pengukuran Kepuasan Kerja Karayawan. Ilman, 3(1), 1-8.

Lengkong, S. P., Permanasari, A. E., \& Fauziati, S. (2015). Implementasi Metode VIKOR untuk Seleksi Penerima Beasiswa. Proceedings of The 7 Th National Conference on Information Technology and Electrical Engineering, 33(September), 107-112.

Opricovic, S. (2004). Compromise solution by MCDM methods: A comparative analysis of VIKOR and TOPSIS. European Journal of Operasional Research, 156, 445-455. 
https://doi.org/10.1016/S0377-

$2217(03) 00020-1$

Rahadjeng, I. R., \& Sumarno, H. (2019). PENERAPAN DATA MINING DALAM PENILAIAN KINERJA GURU TETAP SD NEGERI KEBALEN 07. Jurnal Pilar, 15(1), 7 14.

Saefudin, S., \& Wahyuningsih, S. (2014). Sistem Pendukung Keputusan Untuk Penilaian Kinerja Pegawai Menggunakan Metode Analytical Hierarchy Process (AHP) Pada RSUD Serang. Jurnal Sistem Informasi, 1(1), 33-37. Retrieved from http://ejurnal.lppmunsera.org/index.php/jsii/article /view/78/74

Santoso, E. D., Fathoni, A., \& Hasiholan, L. B. (2018). DEVELOPMENT OF EMPLOYEE PERFORMANCE APPRAISAL OF HONDA SEMARANG SERVICE CENTER BODY \& PAINT DEPARTEMENT WITH BEHAVIORALLY ANCHOR RATING SCALE MODEL. Journal of Management, 4(4).

Sejahtera, P. W. I. (2019). Data Karyawan. Jakarta.

Siti Noni Evita,Wa Ode Zusnita Muizu, R. T. W. A. (2017). Penilaian kinerja karyawan dengan menggunakan metode behaviorally anchor rating scale dan management by objectives. Pekbis Jurnal, 9(1), 18-32.

Sutrikanti, N., Situmorang, H., \& Nurdiyanto, H. (2018). Implementasi Pendukung Keputusan Dalam Pemilihan Calon Peserta Cerdas Cermat Tingkat SMA Menerapkan Metode VIKOR. Jurnal Riset Komputer, 5(2), 109-113.

Ulfa, Maria, Ridwan, M. (2015). RESOURCES SCORECARD DI BMT LOGAM MULIA. Equilibrium: Jurnal Ekonomi Syariah, 3(2), 311-339.

Wijaya, I., \& Mesran, M. (2019). Penerapan Metode AHP dan VIKOR Dalam Pemilihan Karyawan Berprestasi. Seminar Nasional Teknologi Komputer \& Sains (SAINTEKS), 1(1). Retrieved from https://prosiding.seminarid.com/index.php/sainteks/article/view/169

Wina Yusnaeni, M. (2019). Laporan Akhir Pemeringkatan Penilaian Kinerja Karyawan Dengan Menggunakan Metode AHP dan Vikor. Jakarta. 
